\title{
Envelhecimento: análise de dimensões relacionadas à percepção dos idosos
}

\author{
Aging: analysis of dimensions related to the elderly's perœption
}

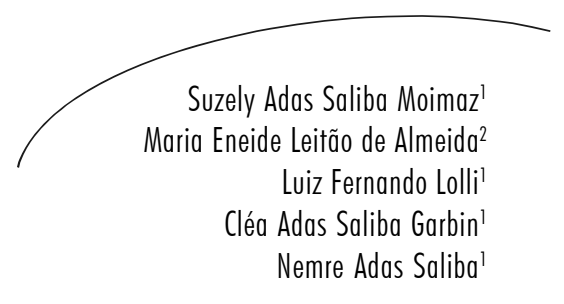

Resumo

Objetivos: Investigar o significado do processo de envelhecimento, bem como os efeitos da assistência odontológica recebida, analisando as repercussões dessas questões na saúde bucal e na vida dos idosos. Métodos: Trata-se de uma pesquisa qualitativa de fundamentação fenomenológica, com amostra intencionalmente definida. Foram selecionados cinco idosos para entrevista, na qual foi utilizado um questionário semiestruturado. Utilizou-se também um diário de campo para a coleta dos dados e expressões dos sujeitos. As variáveis consideradas foram: o significado do processo de envelhecimento para os idosos, a percepção do envelhecimento pela boca, a experiência pregressa de atendimento odontológico e a influência desses aspectos na qualidade de vida. $\mathrm{O}$ processamento das informações ocorreu por análise e

Palavras-chave:

Envelhecimento.

Saúde Bucal.

Assistência

Odontológica para

Idosos. Pesquisa

Qualitativa. Análise

Qualitativa. Auto-

Imagem.

Autopercepção.

1 Universidade Estadual Paulista-Unesp, Faculdade de Odontologia de Araçatuba. Araçatuba, SP, Brasill

2 Universidade Federal do Ceará, Faculdade de Farmácia, Odontologia e Enfermagem. Fortaleza, CE, Brasil.

Correspondência / Correspondence

Luiz Fernando Lolli

Universidade Estadual Paulista Júlio de Mesquita Filho

Faculdade de Odontologia de Araçatuba, Departamento de Odontologia Social

Rua José Bonifácio, 1193 - Vila Mendonça, Caixa-Postal: 341

16015-050 - Araçatuba, SP, Brasil

E-mail: luphernan@hotmail.com 
em assistência mutiladora, necessidade de tratamento e cuidados preventivos. Conclusões: A dificuldade na mastigação e a perda da capacidade de saborear os alimentos são problemas apontados pelos idosos. A insatisfação estética está diretamente ligada à ausência de dentes e é determinante para desencadear sensações negativas na autoestima dos indivíduos, tendo repercussão nas relações sociais.

\section{Abstract}

Objective: To investigate the influence of the aging process and the effects of dental care received by analyzing the impact of these issues in oral health and the lives of elderly. Methods: This is a qualitative study of a phenomenological framework, with an intentionally set sample. We selected five elders to interview, in which we used a semistructured questionnaire. We also used a diary to collect data and expressions of the subjects. The variables considered were: the meaning of aging for older people, the perception of the aging mouth, past experience of dental care and the influence of these aspects on quality of life. Data was processed was by the analysis and categorization of content. Results: The search resulted in the establishment of categories of "aging", considering the usefulness of the elderly, acceptance, lifestyle, physical limitations and changes in the mouth, the category of "psychosocial aspect of the mouth in old age with chewing, which represents the movement carried out by mouth arrest, grinds, and swallows, eroticism and language, and the category "dental care", subdivided into crippling assistance, need for treatment and preventive care. Conclusions: The difficulty in chewing and loss of ability to taste foods are problems raised by the elderly. Aesthetics dissatisfaction is directly linked to the absence of teeth and is essential to trigger negative feelings of self-esteem among individuals, taking effect on social relations.
Key words: Aging. Oral Health. Dental

Care for Aged.

Qualitative Research. Qualitative Analysis. Self concept.

Qualitative Analysis. Dental Care.
INTRODUÇÃO

O envelhecimento da população mundial representa um trunfo para a humanidade, porém traz um desafio social de estruturação para atendimento das necessidades desse grupo.

O processo de envelhecimento fisiológico causa na boca poucos eventos desencadeadores de disfunções e incapacidades, mas grande número de estudos revela que, de modo geral, a condição de saúde bucal dos idosos é deficiente. ${ }^{1-3}$

Dados epidemiológicos apontam que o Brasil é caracterizado como o "país dos desdentados", fator que muito provavelmente detém relação com o tipo de assistência odontológica recebida durante a vida. O levantamento das condições de saúde bucal da população brasileira ${ }^{4}$ demonstrou que o índice CPO-D (referente ao número de dentes cariados, perdidos ou obturados) para o 
grupo etário de 65 a 74 anos foi de 27,93. Isto significa que cada pessoa desse grupo possuía apenas quatro dentes livres de cárie e de suas consequências (obturação/extração). ${ }^{5}$

A maior parte dos trabalhos que avaliam as mudanças no estado de saúde bucal de indivíduos e populações está baseada em indicadores clínicos da doença, existindo relativamente poucas avaliações voltadas à saúde e bem-estar a partir da percepção do indivíduo. ${ }^{6}$ Outro aspecto que reflete a debilidade no trato com essa parcela da população está ligado à falta sistemática de pesquisas nessa área, além da frágil introdução das disciplinas relacionadas ao envelhecimento (Geriatria e Gerontologia) no currículo acadêmico, colocando, assim, um desafio para os profissionais que trabalham a temática. ${ }^{6}$ Apesar disso, é crescente o interesse de se pesquisar não só as alterações físicas do corpo, mas o que essas alterações podem representar na dimensão psicossocial e na qualidade de vida das pessoas. Tais avaliações, realizadas por meio da autopercepção, oferecem uma ótica diferente das informações obtidas na avaliação clínica. ${ }^{7}$ Por meio da autopercepção, atitudes individuais poderão levar à mudança de comportamento de uma comunidade, de forma que indicadores desse tipo de análise são ferramentas importantes para a implantação de serviços de atenção voltados para um determinado extrato populacional. ${ }^{8}$

A literatura sobre "autopercepção" na área de Odontologia mostra que ela está relacionada a alguns fatores clínicos, como número de dentes cariados, perdidos ou restaurados, e a fatores subjetivos, como sintomas das doenças e à capacidade da pessoa sorrir, falar ou mastigar sem problemas, além de também ser influenciada por fatores como classe social, idade, renda e sexo. ${ }^{9}$

Este trabalho teve como objetivo investigar o significado do processo de envelhecimento e suas repercussões na boca e na vida dos idosos, demonstrando a maneira como o idoso lida com a velhice, como sente e interpreta o adoecimento do corpo e da boca, além de analisar o quanto a assistência odontológica o afetou e afeta no decorrer da vida.

\section{METODOLOGIA}

Trata-se de uma pesquisa qualitativa, com apoio teórico na fenomenologia, que expressa uma preocupação em descrever as características do fenômeno social, ou seja, compreender e explicar a dinâmica das relações sociais expressas em crenças, valores, atitudes e hábitos. ${ }^{10}$

Inicialmente, o projeto foi aprovado pelo Comitê de Ética em Pesquisa com Seres Humanos da Faculdade de Odontologia de Araçatuba (FOA-Unesp), através do parecer 2002/01712, e somente após o consentimento dos participantes é que a pesquisa se iniciou.

Foram selecionados como participantes, de forma intencional, cinco idosos, com distintas características educacionais, econômicas e sociais, residentes no município de Araçatu- 
ba, região noroeste do Estado de São Paulo. Como critério de inclusão, foi considerado o fato de o participante possuir mais de 60 anos, ser independente e detentor de atividades cognitivas sem alterações funcionais. A estes foram atribuídos nomes fictícios, de modo a preservar o anonimato recomendado pelos preceitos éticos. Assim, os autores envolvidos e os respectivos perfis foram:

Sra. Maria: 75 anos de idade, divorciada há mais de 30 anos e tem duas filhas. Formada em pedagogia e aposentada com 10 salários mínimos. Reside em casa própria com uma filha e um neto. É portadora de prótese total superior e removível inferior.

Sra. Fernanda: 68 anos, solteira e com o ensino fundamental incompleto, domésti$\mathrm{ca}$, reside com duas irmãs e possui renda de um salário mínimo. Portadora de prótese total superior e inferior.

Sr. Pedro: 75 anos, ensino fundamental incompleto, divorciado, pedreiro aposentado com um salário mínimo e que reside em um abrigo de idosos. Portador de prótese total superior e inferior.

Sr. Marcelo: 75 anos de idade, vive com a esposa e dois filhos. É aposentado com 14 salários, tendo sido técnico de um laboratório de prótese. Portador de prótese total inferior, prótese parcial removível e prótese fixa na arcada superior. Os demais elementos são naturais.

Sra. Rebecca: 77 anos, nacionalidade síriolibanesa. Teve dois filhos e é divorciada.
Reside em casa própria, estudou o ensino fundamental e tem sua renda (não informada) oriunda do aluguel de imóveis. Possui uma prótese fixa e uma parcial removível na arcada superior, sendo os demais dentes naturais.

A intencionalidade da amostra foi justificada porque em pesquisas desta natureza, o importante é o aprofundamento dos assuntos e não a superficialidade.

Os idosos foram entrevistados em suas residências (no abrigo, em se tratando do Sr. Pedro), em horários previamente agendados e que não interferissem com o bemestar dos mesmos. O recurso utilizado para a obtenção dos dados foi entrevista semiestruturada apoiada em instrumento (questionário) semiestruturado, com gravação em fita cassete, sendo transcrita imediatamente no editor de texto computacional Word ao término da sessão. Adicionalmente para a coleta dos dados, utilizou-se um diário de investigação que consistia num documento que permitiu anotar todas as informações de campo, como as observações e reflexões que foram realizadas sobre as expressões verbais dos sujeitos, descrevendo-as e relacionando-as com a compreensão da situação em estudo.

As variáveis consideradas no instrumento de análise foram: o significado do processo de envelhecimento para os idosos, a percepção do envelhecimento pela boca, a experiência pregressa de atendimento odontológico e a influência desses aspectos na qualidade de vida. 
Após a transcrição dos textos para o computador, foram realizadas leituras exaustivas para o estabelecimento de categorias que pudessem expressar com alta fidelidade os relatos dos idosos. As falas não foram alteradas, tampouco corrigidas em termos de acentuação e gramática. O processamento das informações ocorreu por análise categorial de conteúdos, segundo preconizado por Bardin. ${ }^{11}$

\section{RESULTADOS}

De acordo com a proposição do trabalho e a natureza dos relatos colhidos, na análise de conteúdo foram estabelecidas algumas dimensões da vida dos idosos que foram categorizadas como: "O envelhecimento", "Aspecto Psicossocial da Boca na Velhice" e a "Assistência odontológica". Além disso, foram definidas subcategorias, conforme demonstra o quadro 1 :

Quadro 1 - Resultado temático da análise categorial de relatos coletados por meio de entrevista semi-estruturada com idosos. Araçatuba, SP.

\begin{tabular}{|l|l|}
\hline Categorias & $\begin{array}{l}\text { Sub-Categorias } \\
\text { Utilidade do idoso } \\
\text { Aceitação } \\
\text { Limitação corporal } \\
\text { Estilo de vida } \\
\text { Alteraçôes da boca }\end{array}$ \\
\hline $\begin{array}{l}\text { O Aspecto Psicossocial da Boca } \\
\text { na Velhice }\end{array}$ & $\begin{array}{l}\text { Manducação } \\
\text { Erotismo } \\
\text { Linguagem }\end{array}$ \\
\hline A assistência odontológica & $\begin{array}{l}\text { Assistência mutiladora } \\
\text { Necessidade de tratamento } \\
\text { Cuidados preventivos }\end{array}$ \\
\hline
\end{tabular}

\section{DISCUSSÃO}

0 Envelhecimento

O processo de envelhecimento envolve múltiplas dimensões que dão um caráter complexo ao fenômeno, e a tentativa de compreensão por uma única ótica - a bio- lógica, por exemplo - torna seu entendimento fragmentado. ${ }^{12}$

Utilidade do Idoso

Esta categoria foi registrada nos fragmentos da fala da Sra. Maria, que revela que o 
idoso é um ser útil e tem valor, pois consegue transformar as perdas naturais do envelhecimento em novas possibilidades para se manter vivo no espaço social.

“[...] então eu não parei assim. Eu sei que tenho 75 anos, que estou velha, mas eu não sinto esse peso da velhice. Eu acho que ainda sou uma criatura útil. Eu cuido de dois netos, dou aulapara minha neta, estou alfabetizando minha neta, ajudo na escola porque ela está um pouco fraca. Eu faço meus trabalhos, eu costuro, então eu acho, não sinto assim o peso de 75 anos."

Nesse caso, há um forte indicativo de que a velhice não é uma doença que se abate sobre o corpo. Ao contrário, há uma constatação clara de que o corpo e a mente realizam com desenvoltura as diversas funções rotineiras, desafiando a idade cronológica. Em relação ao próprio envelhecimento, a entrevistada adota uma postura de aceitação quando se refere a sua experiência de vida, pois não vê o processo como peso, mas como algo que deve ser vivido, sempre buscando motivação. Além disso, as aprendizagens obtidas através de suas experiências propiciaram a satisfação de viver sem sentir o ônus da idade.

Na sociedade capitalista, o trabalho representa um grande evidenciador da qualidade de uma pessoa. Isto pode ser evidenciado nas imagens dos idosos, ao relatarem a velhice como perda de capacidade laborativa ou quando citam o "fenômeno" da aposentadoria. $^{13}$
Aceitação

O que vai determinar a capacidade de aceitação e o modo de envelhecer é a conduta de cada pessoa. Ao contrário do depoimento de dona Maria, em que há aceitação do processo, no relato de dona Fernanda ocorre o inverso:

"Olha, eu não acho assim eu tão envelhecida. Eu não acredito que eu tou... en acho sempre en jovem..."

A Sra. Fernanda está satisfeita com sua imagem, cuida da sua saúde e não sente que está envelhecendo. Há aqui uma tendência, muito comum, de não querer o envelhecimento ou negar que ele está presente.

A cultura social privilegia a juventude e a beleza. Com isso, as pessoas idosas tendem a evitar a classificação da velhice. Para isso recorrem aos mecanismos tradicionais de pintar cabelo a fazer reparos no corpo, seguindo o que a sociedade dita como moda, temas de interesse e condutas para se manterem jovens, inclusive negando a idade. ${ }^{14}$

\section{Limitação corporal}

O movimento e o envelhecimento são dois termos que estão intimamente ligados, pois a movimentação do ser humano não é somente um ato mecanicista de músculos, ossos e ligamentos articulando-se em direção ao objetivo determinado, mas uma resposta consciente que comanda o corpo através de sinais cerebrais. A capacidade para 
mover-se e sua importância residem não somente na descoberta de ter ou não saúde, mas em autonomia, no reconhecimento do próprio corpo e do processo de envelhecimento.

O Sr. Marcelo, de 70 anos de idade, quando questionado sobre como está envelhecendo, respondeu:

'Primeiramente vou parar de jogar futebol. As minhas pernas enfraqueceu um pouquinho... então en falei: Já esta na hora de começar a parar. A gente leva um tombo, macbuca, vai demorar muito pra cicatrizar, então a primeira coisa foiparar de jogar futebol."

Este depoimento relata a visão estereotipada da sociedade, pois relacionam o envelhecimento à fragilidade, doenças e perda de vitalidade. O encontro entre o corpo e suas limitações através das dores reflete o amplo sentimento negativo que incorpora uma sensação de incompetência para o movimento. Estudo realizado no município de São José - SC demonstrou, corroborando outros dados da literatura, que aproximadamente $88 \%$ dos idosos são muito ativos fisicamente e $54,1 \% \mathrm{da}$ amostra geral declararam que o estado de saúde dificulta a realização de atividade física. ${ }^{15}$

Além das limitações corporais naturais, a velhice tem sido apresentada como fenômeno social destrutivo, contribuindo para que o idoso seja identificado com fracasso, incapacidade e sofrimento, culminando com exclusão. O idoso assimila tais características e responde a elas de distintas for- mas, variando da passividade, comportamento depressivo e isolamento, à postura agressiva, rebeldia e intransigência. ${ }^{16}$

\section{Estilo de vida}

O meio social e cultural, em adição à carga genética herdada de nossos familiares, além das histórias pessoais, influenciam nas posturas corporais e sociais e podem influenciar no processo saúde-doença. Através do depoimento abaixo, percebe-se como os hábitos de vida se incorporaram ao cotidiano do Sr. Pedro.

"Na época en bebia demais, né? Então eu
acho que isso começou a me envelhecer. Acho,
não! Tenho certera porque o álcool diminui a
alimentação da pessoa. Eupouco me alimen-
tava, aí foi indo, eu fui perdendo a força e
perdendo também os amigos, familia e tudo
mais, né? Eu ia levando a vida como Deus
queria, né? Eu fiquei meio acabado por causa
disso mesmo, né? Calculo que sim. Calculo
não, eu tenho certera por causa da bebida que
não alimentava legal."

Para o Sr. Pedro, a bebida teve ação decisiva no processo de envelhecimento e alteração de sua relação com as pessoas e o mundo.

Em pesquisa realizada no México, idosos relataram que o consumo de álcool e drogas, além de outros hábitos deletérios, está diretamente relacionado à insatisfação com a vida, pois através deste surgem os problemas com a saúde, conflitos familiares e dificuldades econômicas. ${ }^{17}$ 
Alterações da Boca

A saúde dos idosos é o resultado de todos os cuidados e agravos a que foram expostos os corpos. No tocante à saúde bucal, isso não é diferente; é até mais acentuado, uma vez que boca é o espelho que reflete, na velhice, as condições desiguais em que as pessoas vivem e trabalham. Atualmente, sabe-se que quando bem tratados, os dentes naturais podem permanecer a vida toda na boca do indivíduo, demonstrando que o edentulismo não é uma consequência natural do envelhecimento. De fato, causas comuns de perda dental são processos altamente controláveis com a tecnologia atual. ${ }^{18}$

Mas como os idosos perceberam o envelhecimento da boca? Em que momento? A Sra. Maria, sendo interrogada, respondeu:

"Sim, a gente envelhece, né? A gente envelheceu. O rosto aqui, esta parte aqui murcha (referindo-se à porção inferior do rosto), não é como o dente natural, porque também o osso vai, né? A gengiva vai murchando e a gente nota que a gente tem... que os traços vão ficando mais envelhecidos."

Aqui, a entrevistada diz ter ficado com a "boca murcha", o que demonstra o efeito negativo da perda dentária na saúde e autoestima. A Sra. Rebecca enfatizou esse aspecto em sua fala:

\footnotetext{
"Ah, completamente outra boca, né? Tudoé diferente, eu achei que não ia chegar nisso e cheguei!"
}

O Sr. Pedro já voltou a sua resposta, mais especificamente à ocorrência de cárie, relatando:

"Foi uma cárie que me deu, até uma vez eu fui num dentista, até meи pai, eu me lembro, eu era mais novo, solteiro, meu paipagou pra en ir ao dentista, en fui [...]. Ai eu peguei e o que eu fir, larguei de mão, né? Aí os dentes foi indo, foi indo estragando. Ai sempre tinha problema, que os dentes iam estragando, ia dar problema. Ai, ou eu arrancava ou eu amolecia com força."

No depoimento transparece a relação existente entre "o problema da cárie que ia surgindo" e o acesso restrito ao dentista ou a cuidados profissionais, fator comum em décadas passadas e até mesmo nos dias atuais, para determinadas regiões. Isso fica evidente na citação: "meu pai pagou, aí eu fui [...]”. Para o Sr. Marcelo, a doença periodontal e a perda dentária foram indicativos de que a velhice estava chegando:

"Ah senti porque eu tinha uma bolsa na boca, então precisei fazer algumas cirurgias, foi tirando uns dentes aí já precisei usar uma removivel. A superior é removivel, agora a inferior éprótese total."

Quando o Sr. Marcelo revela possuir bolsa, na verdade está se referindo à doença periodontal.

Esses relatos caracterizaram que, sendo uma ou outra doença, ambas contribuem para que o idoso perceba a velhice por meio de alterações patológicas, ou seja, de forma 
mais intensa do que o processo natural de envelhecimento.

\section{ASPECTO PSICOSSOCIAL DA BOCA NA VELHICE}

A boca, antes de ser um órgão, representa um território, um local nobre no corpo humano, por carregar a missão biológica de sobrevivência física (por meio da alimentação), sobrevivência social (comunicação), autoestima e autovaloração (estética / boa aparência), aspectos afetivos (num beijo), dentre outros. Portanto, a boca não pode ser analisada única e exclusivamente como uma simples parte do corpo, mas como porta de entrada e saída para a vida.

\section{Manducação}

Este termo representa o movimento realizado pela boca que apreende, tritura, insaliva e deglute os alimentos. Ao ser questionado sobre a falta dos dentes e qual a maior dificuldade para realizar atividades diárias, o Sr. Pedro revelou:

"Ah. Na alimentação. Não era tudo que eu podia comer não. Quando eu estava sem os dentes, eu fiquei uns 10 anos. Acho que uns 10 anos sem os dentes, eu comia direto, né, direto, como se diria. Tinha as coisas que en não podia comer."

Comer direto significa comer o alimento em pedaços quase que inteiros, sem executar a desintegração mecânica.
A Sra. Rebecca lembrou da dificuldade que teve quando começou a usar prótese inferior:

"Muita dificuldade. Agora que en eston começando porque na hora de mastigar, até verdura que eu tenho que mastigar, eu não estou conseguindo mastigar direito. Ainda dói a gengiva."

Estudos demonstram que os indivíduos dão mais importância aos sintomas e aos impactos funcionais das doenças do que aos sinais visíveis na boca. Em outras palavras, é no momento de utilizar a mastigação que se percebe a falta dos dentes. ${ }^{19,20}$

\section{Erotismo}

Ao abrir a boca para o dentista, as pessoas não estão só demonstrando um órgão, estão demonstrando parte de si; de certa forma, parte de sua personalidade, do seu jeito de ser e do autocuidado. Assim, por vezes, as pessoas podem se sentir reprimidas por alterações da boca, de modo que tal fator intervenha negativamente na sua autovaloração de beleza e vigor. É o que demonstra o relato do Sr. Pedro:

"Eu na roça, arrancava a cana com os dentes. Aspessoas falavam: Esse cara é um leão. Chamavam que eu tinha os dentes bons, fortes, bonitos."

Seguindo o pensamento de que a presença dos dentes é sinônimo de beleza, a Sra. Maria indica que a beleza é a primeira coisa que se perde quando se mutilam os dentes: 
"Porque a perda do dente é terrivel. Muda a vida da gente todinha. Primeiro a estética, já é feio, não é o dente da gente, o perigo de cair, quando a gente fica doente tem que tirar, né."

A Sra. Rebecca expressa o valor da boca e a relação que a mesma tem com o corpo e o psicológico:

"Eu acho que a boca é tudo, né. Sorrir, comer, beber... Tem coisa melhor do que uma boca? Eu acho que não tem, no corpo da pessoa não tem coisa melhor. É tudo, né?"

As consequências psicológicas da retirada dos dentes podem chegar a situações complicadas. A Sra. Maria expressa:

"Se vai tirar seus dentes, opsicólogo tinha que dar uma conversada com você, falar, preparar teu espirito, que não é todo o mundo que aceita, é um negócio que marca um pouco, né? E tem pessoas que perdem metade da vida mesmo para enfrentar depois essa situação. Não sorrir mais, né, por causa do problema."

$\mathrm{Na}$ realidade, a sexualidade no idoso é sempre revestida de muitos tabus. Os idosos desdentados podem ainda desfrutar de uma vida sexual, embora se saiba que as atividades sexuais em grande parte concentram-se no prazer oral e este poderá estar abalado em função de precárias condições dentárias e periodontais. ${ }^{21}$ Fica a questão: a retirada dos dentes em determinadas condições poderia ser considerada como castração bucal?
Linguagem

Como orifício, a boca é física e simbolicamente a porta de passagem para aquilo que chega do exterior para dentro do corpo, e sai do interior para fora, constituindo um elemento de comunicação por excelência. ${ }^{22}$

Neste tópico, foram investigadas as dificuldades encontradas na fala quando da utilização ou não de prótese. Obteve-se como resultado:

"Todo mundo sabe que a pessoa quando não tem os dentes fala com a boca murcha, como falava, né, com a boca murcha, né, conversava." (Sr. Pedro).

"Não, na fala não, eu sobre a fala assim, me adaptei muito bem."(Sra. Fernanda).

De modo geral, os idosos desta pesquisa acreditam que as dificuldades encontradas com o uso da prótese sejam normais, sendo um período de adaptação e não constituem problema para a fala.

\section{A ASSISTÊNCIA ODONTOLÓGICA}

Assistência Mutiladora

A prática da Odontologia restauradora tradicional era, há três décadas, calcada no diagnóstico, quase que exclusivamente da cárie e no reparo da lesão, ou confecção de restauração dentária. $\mathrm{Na}$ impossibilidade de tratá-las, optava-se pela extração do dente portador de cárie. O resultado desta práti- 
ca foi alta proporção de perda dentária, com predomínio da assistência mutiladora.

A história da Sra. Maria, ocorrida na década de 50 , ilustra um pouco essa afirmação:

"Quando eu era mocinha, eu tratava os dentes, naquele tempo não tinha muito dentista, né? Tinha os dentistas que chamavam de práticos, não era os dentistas formados. Formado era muito pouco. Então a gente ia tratar com o dentista formado, mas eles tinham muitos clientes, porque como eram poucos, eles então ficavam naquela troca de algodão. Trocavam o algodão no dente e o dente ia então estragando mais. Então chegavam a obturar 0 dente, a cárie já estava muito grande e a gente estava quase perdendo o dente."

Necessidade de tratamento

Somente um idoso relatou ir ao dentista regularmente, independentemente de sentir alguma dor ou incômodo:

"Geralmente a cada seis meses eu passo lá pra ele der uma verificada assim, ver comoé que está. Ai ele diz assim: tá bem, pode continuar, não precisa refazer nada e vai tocando a vida do jeito que está." Sr. Marcelo.

De um modo geral, as necessidades de tratamentos são percebidas de formas diferentes em diferentes pessoas e isso depende das características demográficas, de disponibilidade de recursos e da predisposição pessoal. Destas, a primeira apenas (idade, sexo, raça) é imutável; a disponibilidade de recursos pode ser alcançada com políticas públicas de acesso e a predisposição com escolaridade, autopercepção e repasse de informações. No Brasil, em inquérito realizado pelo Ministério da Saúde, ${ }^{4}$ os dados apontaram que os 5.326 entrevistados, $55 \%$ responderam necessitar de algum tratamento odontológico. Esse resultado foi superior aos encontrados nos EUA (46\%) por Slauther \& Taylor $^{23}$ e no Sri Lanka (43\%) por Ekanaiake \& Pereira. ${ }^{20}$ Além do mais, no estudo brasileiro, foi demonstrada associação positiva entre a percepção da necessidade de tratamento e péssimas condições bucais, à presença de dor nos últimos seis meses e com pessoas que foram esclarecidas sobre cuidados bucais. ${ }^{24}$

No presente trabalho, para dois idosos, um que reside no abrigo de idosos e outra que é aposentada com um salário mínimo, houve a percepção da necessidade de substituição da prótese, mas eles vincularam tal necessidade à condição financeira.

"Eu tava até com vontade de falarpro meu filho, se ele pagasse, eu mandava fazer uma (prótese) pra mim." (Sr. Pedro).

Nos estudos de Heft, ${ }^{19}$ a condição socioeconômica se mostrou relacionada à percepção dos idosos quanto a cuidados bucais. Porém, grande parte dos trabalhos da literatura não verificou, ou ao menos não citou tal associação.

Cuidados preventivos

Os cuidados com a boca e a saúde foram sabiamente evidenciados pelo Sr. Marcelo: 
"A boca é o fator mais importante pra saúde da gente, né? Porque muitas doenças a gente contrai épela boca. A parte de... como qualquer coisa assim, não mastiga direito. Se não entrarpela boca, a pessoa vive inteiro, mas às vezes entrando pela boca pode criar qualquer doença."

Quando foram interrogados sobre os cuidados com a prótese e a forma como higienizam a cavidade bucal, obtivemos as seguintes respostas:

"De manhã cedo eu levanto epasso uma escoa e limpo com pasta epronto, uma vez cedo, né, senão às vezes, quando eu almoço, na hora do almoģo também, eu vou e limpo, né, a comida que eu como, a comida pesada que eu sinto, aí eu vou lá e limpo." (Sr. Pedro)

"Ah, eu limpo toda a vez que eu tenho qualquer coisa que me implica, assim, como se fosse os meus dentes, qualquer coisa que eu sinta que esta presa, eu vou e tiro, já escovo." (Sra. Maria)

Conforme verificado, a limpeza constante e após as refeições nem sempre é realizada pelos participantes deste estudo. Em geral, só a limpeza matinal é realizada e as demais ficam na dependência de que algum alimento grude.

Na realidade, trabalhos demonstram que a autopercepção está mais relacionada ao grau de escolaridade, idade e a situações adversas como desinformação, condições bucais desfavoráveis, falta de dentes, presença de mobilidade e cárie, ${ }^{20,25}$ o que ressalta a importância das atividades de educação em saúde.
Em relação aos cuidados com o aparelho, todos os idosos confirmaram que dormem com a prótese. Somente o Sr. Pedro recebeu orientação sobre a retirada da prótese para dormir, a partir dos estudantes universitários. Os demais relataram nunca ter recebido tal orientação.

"Eu tinha que obedecer, né, eles são estudantes, então eu fiz uma semana. Eu fiz assim, dormir sem a dentadura, mas eu não acostumo. Já procurei acostumar, mas não adianta." (Sr. Pedro)

"Não, ninguém nunca falou nada, e eu não tiro não, eu tiro assim um pouquinho às vezes se estiver machucando porque eu tenho muita afta." (Sra. Maria)

Ao serem questionados sobre a satisfação acerca do atendimento odontológico que receberam durante toda a vida, dois deles lembrou que no começo havia poucos dentistas, o tratamento era mais difícil e a Odontologia não tinha e tecnologia e os recursos que tem hoje:

"No começo não, quando eu comecei a tratar dente era mocinha, o tratamento era muito fraco. Eles estragavam muito os dentes da gente porque você ia fazer o tratamento, eles punbam algodãozinho com óleo de cravo, e ai tirava aquele algodãozinho, ia lá outro dia tirava aquele algodãozinho, então demorava muito pra obturar um dente. Quando ia obturar um dente, já estava quase todo estragado. Pode também ter isso também, que a gente... que os antigos estejam perdendo os dentes mais depressa porque eram poucos os dentistas. Hoje tem muito." (Sra.Maria) 
"Para a minha saúde foi muito bom, porque com os dentes que eram doentes, então, a gente engolia aquilo que não fazia bem, poderia causar qualquer doença. Então eu tinha que tirar porque a piorreia dar aquele pus, né, o dente cresce. Teve alguns que eu consegui até tirar sozinha. Então não tive alternativa." (Sra. Fernanda)

Em ambas as citações, nota-se ressentimento pela extração dos dentes, mas a Sra. Fernanda encara isso com tranquilidade, dizendo que foi o melhor para a sua saúde.

Existe, na literatura, citação da dificuldade de acesso ao tratamento odontológico, pela escassez de profissionais na época ou pelo fato de se viver na zona rural, além do fator alto custo dos tratamentos ou a própria mentalidade, tanto da população quanto dos profissionais. Estes foram fatores que contribuíram para que as perdas ocorressem em idades tão precoces, resultando em elevado edentulismo. Os discursos referem que o cirurgião-dentista desempenhou papel importante na perda precoce de dentes, uma vez que em muitos casos a decisão pelas exodontias foi fortemente influenciada pelo profissional. ${ }^{26}$ Analisandose a outra face da moeda, na perspectiva do profissional da saúde na atenção ao idoso, trabalho recente apontou que a atividade das equipes de saúde da família representa, na opinião dos profissionais, a grande estratégia para o estabelecimento de cuidados mais apropriados, sejam de promoção de saúde, cuidados preventivos ou de reabilitação. Por estarem inseridas nos lares dessas pessoas, acabam possuindo com elas uma relação de vínculo. Adicionalmente, reconhecem que $o$ atendimento sempre foi centrado no aspecto curativo e no atendimento à demanda. ${ }^{27}$ Com isso, atualmente os profissionais consideram a importância das ações de promoção de saúde, do vínculo entre eles e os pacientes e a relação de confiança que isso gera.

\section{CONCLUSÃO}

Os idosos interpretam o processo de envelhecimento e o adoecimento do corpo de diferentes formas, dependendo do seu histórico de vida. Quanto à saúde bucal, a dificuldade de saborear os alimentos e a limitação mastigatória representam problemas enfrentados por essa classe. A insatisfação estética desencadeia estímulos negativos na autoestima e autovaloração do indivíduo, tendo impacto direto nas relações sociais e afetivas. 


\section{REFERÊNCIAS}

1. Colussi CF, Freitas SFT, Calvo MCM. Perfil epidemiológico da cárie e do uso e necessidade de prótese na população idosa de Biguaçu, Santa Catarina. Revista Brasileira de Epidemiologia 2004 mar; 7(1): 88-97.

2. Reis SCGB, et al. Condição de saúde bucal de idosos institucionalizados em Goiânia, GO. Revista Brasileira de Epidemiologia 2005 mar; 8(1): 67-73.

3. Benedetti TRB, Mello ALSF, Gonçalves LHT. Idosos de Florianópolis: autopercepção das condições de saúde bucal e utilização de serviços odontológicos. Ciência em Saúde Coletiva 2007 dez; 12(6): 1683-90.

4. Brasil. Ministério da Saúde. Projeto SB Brasil 2003: condições de saúde bucal da população brasileira 2002-2003: resultados principais. Brasília: Ministério da Saúde; 2004.

5. Moreira RS, et al. A saúde bucal do idoso brasileiro: revisão sistemática sobre o quadro epidemiológico e acesso aos serviços de saúde bucal. Cadernos de Saúde Pública 2005 nov/dez; 21(6): 1665-75.

6. Silva DD, Sousa MLR, Wada RS. Autopercepção e condições de saúde bucal em uma população de idosos. Cadernos de Saúde Pública 2005 ago; 21(4): 1251-9.

7. Reisine ST. The impact of dental conditions on social functioning and the quality of life. Annual Review of Public Health 1988; 9: 1-19.

8. Henriques C, et al. Auto-percepção das condições de saúde bucal de idosos do município de Araraquara - SP. Ciência Odontológica Brasileira. 2007 jul./set; 10 (3): 67-73.
9. Silva SRC, Fernandes, RAC. Autopercepção das condições de saúde bucal por idosos. Revista de Saúde Pública 2001; 35(4): 349-55.

10. Minayo CS. O desafio do conhecimento: pesquisa qualitativa em saúde. 10. ed. São Paulo: Hucitec; 2007.408 p.

11. BARDIN L. Análise de conteúdo. Lisboa: Edições 70, 2006. 223p.

12. Cabral PKGF. Idosos reconstruindo-se com suas histórias [dissertação]. São Paulo. Pontifica Universidade Católica. Programa de Pós-Graduação em Gerontologia, 2002.

13. Guerra ACLC, Caldas CP. Dificuldades e recompensas no processo de envelhecimento: a percepção do sujeito idoso. Ciência \& Saúde Coletiva 2007 [online]. Disponível em: < http:// www.abrasco.org.br/ cienciaesaudecoletiva/artigos/ artigo_int.php?id_artigo $=2917>$

14. Freitas EV, et al . Tratado de Geriatria e Gerontologia. 2. ed. Rio de Janeiro: Guanabara Koogan, 2006.

15. Cardoso AS, et al. Percepção subjetiva de saúde e nível de atividade física de idosos. Revista Brasileira de Geriatria e Gerontologia. 2008; 11(1): 81-91.

16. Joia LC, Ruiz T, Donalisio MR. Condições associadas ao grau de satisfação com a vida entre a população de idosos. Rev Saúde Pública 2007; 41(1): 131-8.

17. Castillo BA, et al. Stressful situations in life, use and abuse of alcohol and drugs by elderly in Monterrey, Mexico. Rev Lat Am Enfermagem 2008 mai/jun; 16(especial): 509-15. 
18. Saliba CA, Saliba NA, Marcelino G. Saúde bucal dos idosos: uma realidade ignorada. Rev Assoc Paul Cir Dent 1999 out; 53: 279-82.

19. Heft MW, et al. Relationship of dental status, sociodemographic status, and oral symptoms to perceived need for dental care. Community Dent Oral Epidemiol 2003; 31(5): 351-60.

20. Ekanayke L, Perera I. Factors associated with perceived oral health status in older individuals. Int Dent J 2005; 55(1): 31-7.

21. Brunetti RF, Montenegro FLB.

Odontogeriatria: noções de interesse clínico. São Paulo. Artes Médicas, 2002.

22. Barbosa LMG. O sentido psicológico da fala: um enfoque psicossocial da gagueira. Revista Fono Atual 1999; 3(7): 8-10.

23. Slauther A, Taylor L. Perceptions of dental care need among african-american elders: implications for health promotion. Spec Care Dentist 2005; 25(3): 158-63.

24. Martins AMEBL, Barreto SM, Pordeus IA. Fatores relacionados à autopercepção da necessidade de tratamento odontológico entre idosos. Rev Saúde Pública 2008; 42(3): 487-96.

25. Marina CS. O processo de envelhecimento no Brasil: desafios e perspectivas. Textos Envelhecimento. 2005; 8(1): 43-60.

26. Hiramatsu DA, Tomita NE, Franco LJ. Perda dentária e a imagem do cirurgião dentista em um grupo de idosos. Ciência \& Saúde Coletiva. 2007; 12(4): 1051-6.

27. Marin MJS, et al. A atenção à saúde do idoso: ações e perspectivas dos profissionais. Revista Brasileira de Geriatria e Gerontologia. 2008; 11: 245258. 